\title{
MODELING OF GAS-SURFACE INTERFACE FOR PARAFFIN-BASED HYBRID ROCKET FUELS IN COMPUTATIONAL FLUID DYNAMICS SIMULATIONS
}

\author{
D. Bianchi, F. Nasuti, and D. Delfini \\ "Sapienza" University of Rome \\ 18 via Eudossiana, Rome 00186, Italy
}

\begin{abstract}
Numerical simulations of the flowfield in a hybrid rocket engine are carried out with a multispecies chemically reacting Reynolds-averaged Navier-Stokes (RANS) solver which includes detailed gas-surface interaction (GSI) modeling based on surface mass and energy balances. The oxidizer is gaseous oxygen which is homogeneously fed into single-port cylindrical grains. The modeling of GSI already developed and validated for pyrolyzing fuels such as hydroxyl-terminated polybutadiene (HTPB), is extended to the case of liquefying fuels, such as paraffin wax. A simplified two-step global reaction mechanism is considered for the gas-phase chemistry to model the combustion process inside the chamber. $\mathrm{Nu}-$ merical simulations performed at different gas/melt-layer interface temperatures and oxygen mass fluxes show a considerable increase of fuel regression rate, in the range of 3 up to 5 times, for the liquefying fuel with respect to the pyrolyzing one. Results show that the regression rate enhancement is significant only when the gas/melt-layer interface of the liquefying fuel is close to the melting temperature. At increasing gas/melt-layer interface temperatures, the regression rate decreases following an inverse power law and gets close to that of a pyrolyzing fuel for the same operating conditions. Finally, regression rate behavior at varying oxygen mass flux of liquefying fuels is not substantially altered from that of pyrolyzing fuels as the oxidizer flux exponent remains rather constant.
\end{abstract}

\section{INTRODUCTION}

The intrinsic properties of hybrid propellant rockets in terms of performance, simplicity, safety, reliability, low development cost, reduced environmental pollution, and flexibility make them one of the envisaged future generation propul-

(C) The Authors, published by EDP Sciences. This is an open access article distributed under the terms of the Creative Commons Attribution License 4.0 (http://creativecommons.org/licenses/by/4.0/). 
sion systems. On the other hand, there are some technical challenges to be overcome before achieving the same level of maturity as solid and liquid traditional systems, such as low regression rate, reduced combustion efficiency, and combustion instability. Therefore, the hybrid rocket engine development requires deeper understanding of the physico-chemical phenomena that control the combustion process and of the fluid dynamics inside the motor. The knowledge of the complex interactions among fluid dynamics, solid fuel regression, oxidizer atomization and vaporization, mixing and combustion in the gas phase, nozzle thermochemical erosion, particulate formation, and radiative characteristics of the gas and the flame can only be improved by combined experimental and numerical research activities.

Especially, low fuel regression rate is one of the most significant shortcoming of conventional hybrid rockets. So far, many techniques (such as swirling oxidizer injection, insertion of diaphragms in the combustion port, use of complex multiport grain configurations, etc.) have been tried to improve the regression rates of hybrid rockets but all of these methods suffer from important drawbacks. One promising technique to solve the slow regression problem relies on the use of paraffin-based fuels. The regression rate of paraffin-based fuels is, in fact, about $3-5$ times higher than that of conventional pyrolyzing fuels, such as HTPB. The low surface tension and low melt layer viscosity of paraffin-based fuels generate a significant entrainment of melted fuel droplets into the oxidizer flow and this additional mass transfer mechanism can potentially increase the regression rate by several times with respect to conventional pyrolyzing fuels. This is, mainly, due to the combined effect of reduced effective heat of gasification, decrease of blocking effect in the boundary layer, and possibly higher heat transfer due to increased surface roughness. Differently from conventional pyrolyzing fuels, in fact, the regression of paraffin-based fuels, thanks to their low melting point, proceeds almost without vaporization and liquid fuel is mainly supplied to the flame zone by the entrainment phenomena that plays a dominant role in determining the regression rate characteristics. For oxidizer mass flux levels encountered in practical hybrid rocket applications, droplet entrainment can dominate direct fuel gasification. Hence, the regression rate model for these liquefying propellants must be based on a completely different mass transfer mechanism involving the entrainment of liquid droplets from the melt layer.

The theoretical [1-3], numerical [4-6], and experimental modeling [7-12] of the flow in the combustion chamber and nozzle of a paraffin-based hybrid propellant rocket has been the subject of considerable interest recently but adequate models are still lacking. The modeling effort is, in fact, challenging and requires the ability to adequately describe the interaction between the reacting flow and the solid surface, which includes the melt-layer, through suitable GSI modeling. The objective of this study is the numerical simulation of the flow inside the combustion chamber and nozzle of a paraffin-based hybrid rocket by solv- 
ing the RANS equations for multicomponent turbulent reacting flows, including the required submodels in order to describe the homogeneous combustion in the gas phase and the fluid-surface interaction among the exhaust gases, the meltlayer, and the paraffin-based solid propellant. The basis of the present analysis is the comprehensive theoretical model for HTPB pyrolysis and combustion in hybrid rocket engines developed and validated in previous studies [13,14], which is extended here to the case of paraffin-based liquefying fuels.

\section{THEORETICAL AND NUMERICAL MODEL}

The study of hybrid rocket engine flowfields requires a suitable modeling of both GSI and gas phase reactions. In the present study, the modeling of GSI already developed and validated for pyrolyzing fuels such as HTPB [13-15] is extended to the case of liquefying fuels in hybrid rocket engines. In particular, a GSI model based on surface mass and energy balances is coupled with a three-dimensional (3D) chemically-reacting computational fluid dynamics (CFD) code. The CFD tool is a finite-volume solver for $3 \mathrm{D}$ turbulent compressible multicomponent reacting flows $[16,17]$ with variable thermodynamic and transport properties. The thermodynamic properties of individual species are approximated by seventhorder polynomials of temperature and the transport properties are approximated by fourth-order polynomials [18]. Mixture properties for conductivity and viscosity are derived from the Wilke's rule. The diffusion model is based on an effective diffusion coefficient obtained assuming a constant Schmidt number.

The Spalart-Allmaras one-equation model [19] is used to compute the turbulent viscosity. Turbulent thermal conductivity and turbulent mass diffusivity are computed from the turbulent viscosity, specific heat at constant pressure, turbulent Prandtl number, and turbulent Schmidt number. The Spalart-Allmaras turbulence model has been selected because of its simplicity and capability to model internal flows in rocket motors, at least at a qualitative level. The chemistry is modeled assuming a zero-dimensional perfectly stirred reactor or laminar flame submodel, i.e., turbulence-chemistry interaction is neglected. The code solves the time-dependent conservation equations of mass, momentum, and energy for the chemical nonequilibrium flowfield and adopts a standard finitevolume Godunov-type formulation. It is second-order accurate in space and uses multiblock structured meshes. The system of equations is approximated by a cellcentered finite-volume scheme. The viscous fluxes are approximated by centered differencing, whereas the convective fluxes are computed by means of the solution of a Riemann problem whose left and right states are reconstructed by an interpolation procedure which uses the minmod limiter. The system of ordinary differential equations is advanced in time by means of an explicit Runge-Kutta integration. 


\subsection{Gas-Surface Interface}

Because of the chemically active surface, further physical modeling is necessary for the GSI. To complete the formulation of the theoretical model, boundary conditions must be specified at the gas-solid interface, which describe the physics of the surface phenomena. The boundary conditions are detailed in the following for both liquefying fuels (such as paraffin wax) and nonliquefying pyrolyzing fuels (such as HTPB).

\subsubsection{Pyrolyzing fuels (hydroxyl-terminated polybutadiene)}

If it is assumed that no material is being removed in a condensed phase (solid or liquid), then the general conservation laws at the gas-solid interface over a pyrolyzing fuel grain can be written as [20]:

$$
\dot{m}_{w}=(\rho v)_{w}=\rho_{s} \dot{r} \quad(\text { Mass })
$$

where $\dot{m}_{w}$ is the overall mass flux injected from the pyrolysis process per unit surface area of the wall; $\rho$ and $v$ are the wall density and the normal-to-wall velocity in the gas phase due to pyrolysis products injection because of grain regression; and, finally, $\rho_{s}$ and $\dot{r}$ are the solid material density and regression rate, respectively;

$$
\rho D_{i m} \frac{\partial y_{i}}{\partial \eta}+\dot{\omega}_{i}=(\rho v)_{w} y_{i}, \quad i=1,2, \ldots, N \quad \text { (Species) }
$$

where $D_{i m}$ is the species-to-mixture diffusion coefficient; $y_{i}$ is the gas phase mass fraction of the $i$ th species at the wall; $N$ is the number of species; $\dot{\omega}_{i}$ is the rate of production of gas-phase species $i$ at the surface due to fuel pyrolysis; and $\eta$ is the inward (from solid to gas) coordinate normal to surface; and

$$
k \frac{\partial T}{\partial \eta}+\sum_{i=1}^{N} h_{i} \rho D_{i m} \frac{\partial y_{i}}{\partial \eta}+\dot{m}_{w} h_{s}=\dot{m}_{w} h_{w}+\dot{q}_{\text {cond }}^{s s} \quad(\text { Energy })
$$

where $h_{w}$ is the enthalpy of the gas mixture at wall; $h_{i}$ is the enthalpy of the single gas species; $h_{s}$ is the enthalpy of the solid grain at the wall temperature; $k$ is the gas conductivity; $T$ is the gas temperature; and $\dot{q}_{\text {cond }}^{s s}$ is the conduction heat flux inside the grain. Note that the term $\dot{m}_{w} h_{s}$ is the energy flux entering the surface due to grain regression. The radiation contributions do not appear in the energy balance as they have not been modeled in the present study.

Concerning the energy transfer into the fuel grain, it is assumed that heat conduction is dominant in the direction normal to the grain surface. Although 
axial temperature gradients exist along the grain wall, they are generally small if compared with the normal heat conduction and represent a second-order effect. In a moving local coordinate system tied to the receding fuel surface, the general one-dimensional (1D) form of the in-depth energy balance (assuming constant material properties) is:

$$
\frac{\partial T_{s}}{\partial t}=\alpha_{s} \frac{\partial^{2} T_{s}}{\partial \eta^{2}}-\dot{r} \frac{\partial T_{s}}{\partial \eta} \quad \text { (Energy in the solid fuel layer) }
$$

where the different terms (from left to right) represent the temporal variation of the grain sensible energy, the net conduction inside the material, and the convected energy due to the coordinate motion. The term $\alpha_{s}=k_{s} /\left(\rho_{s} c_{s}\right)$ is the fuel grain thermal diffusivity and $T_{s}$ is the grain local temperature. Assuming steady-state condition and integrating the stationary form of Eq. (3) between gas-fuel interface $w$ and a point sufficiently far from the wall so that an adiabatic condition can be assumed for the fuel at initial state $i$, the steady-state conduction term $\dot{q}_{\text {cond }}^{\text {ss }}$ can be expressed as:

$$
\dot{q}_{\mathrm{cond}}^{s s}=\rho_{s} \dot{r} c_{s}\left(T_{w}-T_{i}\right)=\dot{m}_{w} c_{s}\left(T_{w}-T_{i}\right)
$$

where $c_{s}$ indicates the fuel heat capacity; $T_{w}$ is the grain wall temperature; and $T_{i}$ is the grain initial temperature. The steady-state assumption is a reasonable approximation when the thermal lag in the solid is sufficiently small, which actually occurs in the operating conditions to be simulated, i.e., moderately high fuel regression rate and low fuel thermal diffusivity.

The energy balance expression can be recasted using Eq. (2) emphasizing the contributions due to convection from the gas, conduction into the solid propellant grain, and chemical reactions, as:

$$
\underbrace{k \frac{\partial T}{\partial \eta}}_{\text {convection }}=\underbrace{\sum_{i=1}^{N} \dot{\omega}_{i} h_{i}-\dot{m}_{w} h_{s}}_{\text {chemical }}+\underbrace{\dot{q}_{\text {cond }}^{s s}}_{\text {conduction }} .
$$

The chemical heat flux can be expressed as:

$$
\dot{q}_{\text {chem }}=\dot{m}_{w}\left(\sum_{i=1}^{N} \frac{\dot{\omega}_{i}}{\dot{m}_{w}} h_{i}-h_{s}\right)=\dot{m}_{w} \Delta h_{\text {pyro }}
$$

where the term in parentheses represents the heat absorbed by the surface reactions and, hence, it represents the so-called heat of pyrolysis, $\Delta h_{\text {pyro. The }}$ rate of production of gas-phase species $i$ at the surface, $\dot{\omega}_{i}$ appearing in Eqs. (2) and (5), has to be estimated on the basis of the fuel pyrolysis model. In this work, according to [21], a single Arrhenius-type equation is used to model $\dot{m}_{w}$ 
Table 1 Heterogeneous rate constants for HTPB [22]

\begin{tabular}{ccc}
\hline Surface reaction & $A, \mathrm{~kg} /\left(\mathrm{m}^{2} \mathrm{~s}\right)$ & $E, \mathrm{~kJ} / \mathrm{mol}$ \\
\hline $\mathrm{HTPB}_{s} \rightarrow \mathrm{C}_{4} \mathrm{H}_{6}$ & 2208 & 56.5 \\
\hline
\end{tabular}

Table 2 The HTPB properties [23,24]

\begin{tabular}{cccc}
\hline $\begin{array}{c}\text { Density } \rho_{s}, \\
\mathrm{~kg} / \mathrm{m}^{3}\end{array}$ & $\begin{array}{c}\text { Specific heat } c_{s}, \\
\mathrm{~J} /(\mathrm{kg} \cdot \mathrm{K})\end{array}$ & $\begin{array}{c}\text { Thermal conductivity } k_{s}, \\
\mathrm{~W} /(\mathrm{m} \cdot \mathrm{K})\end{array}$ & $\begin{array}{c}\text { Heat of pyrolysis, } \\
\mathrm{MJ} / \mathrm{kg}\end{array}$ \\
\hline 960 & $1632[24]$ & $0.217[24]$ & $1.1[23]$ \\
\hline
\end{tabular}

assuming that the main product of $\mathrm{HTPB}$ pyrolysis is 1,3 -butadiene $\left(\mathrm{C}_{4} \mathrm{H}_{6}\right)$. In particular, the rate of pyrolysis is obtained as

$$
\dot{m}_{w}=A \exp \left(-\frac{E_{a}}{R T_{w}}\right)
$$

where $T_{w}$ is the wall temperature and $A$ and $E_{a}$ are the preexponential factor and the activation energy for the pyrolysis reaction, respectively. Coefficients are taken as reported in Table 1, according to Arisawa and Brill [22]. As a single pyrolysis product is assumed, the species production rate at the fuel surface, $\dot{\omega}_{i}$, is equal to $\dot{m}_{w}$ for species $\mathrm{C}_{4} \mathrm{H}_{6}$ and to zero for all the remaining gas-phase species. However, it is important to note that, although the only pyrolysis gas considered here is 1,3-butadiene, the gas mixture at the fuel surface is not entirely composed of $\mathrm{C}_{4} \mathrm{H}_{6}$ as the other gaseous species (both oxygen and combustion gases) can actually reach/leave the surface due to diffusion and convection induced by blowing. The mixture composition at the HTPB wall, in fact, is solved enforcing the species surface mass balance, Eq. (2) coupled with the surface energy balance, Eq. (5). This is very important as solving both the mass and species balances Eqs. (1) and (2) guarantees that the correct amount of fuel is injected in the flowfield from the grain surface.

In Table 2, the HTPB properties used for the simulations are listed. The heat conducted in the solid grain is modeled according to Eq. (4) where a constant specific heat has been assumed for the solid HTPB, according to [24]. The solid fuel thermal conductivity $k_{s}$ is also assumed constant with temperature. Finally, a value of $1.1 \mathrm{MJ} / \mathrm{kg}$ has been assumed for the heat of pyrolysis of HTPB as performed in [25]. The heat of pyrolysis could be evaluated from Eq. (6) and the assumption that the pyrolysis gas is only composed of 1,3-butadiene, however, since this assumption is an approximation, in this work the heat of pyrolysis has been derived from the available experimental data [23]. 


\subsubsection{Liquefying fuels (paraffin wax)}

If it is assumed that the material is dominantly removed by the entrainment phenomena (negligible evaporation, boiling, or pyrolysis fuel removal process), then the general mass conservation at the gas/melt-layer interface over a liquefying fuel grain can be written as

$$
\dot{m}_{\mathrm{ent}}=\rho_{l}\left(v_{l}+\dot{r}_{l}\right)
$$

where $\dot{m}_{\mathrm{ent}}$ is the overall mass flux injected due to the entrainment phenomena per unit surface area of the wall; $\rho_{l}$ is the liquid material density; $v_{l}$ is the liquid velocity perpendicular to the surface in the melt-layer; and $\dot{r}_{l}$ is the gas/meltlayer interface regression rate. From the melt-layer/solid interface mass balance, the liquid velocity in the melt-layer $v_{l}$ is expressed as $\left(\rho_{s} / \rho_{l}-1\right) \dot{r}_{s}$ where $\dot{r}_{s}$ is the melt-layer/solid interface regression rate. If the steady-state condition is assumed (constant thickness of the melt-layer), then the gas/melt-layer interface regression rate and the melt-layer/solid interface regression rate are equal so that $\dot{r}_{l}=\dot{r}_{s}=\dot{r}$ and the entrainment mass flux becomes

$$
\dot{m}_{\mathrm{ent}}=\rho_{s} \dot{r} .
$$

Paraffin wax $\left(\mathrm{C}_{32} \mathrm{H}_{66}\right)$ is assumed to decompose/gasify into $\mathrm{C}_{2} \mathrm{H}_{4}$ and molecular hydrogen through the cracking reaction $\mathrm{C}_{32} \mathrm{H}_{66} \Rightarrow \mathrm{H}_{2}+16 \mathrm{C}_{2} \mathrm{H}_{4}$. As a singlephase approach is used in this study, the cracking of the entrained liquid droplets and the associated heat of cracking are not modeled, and gaseous $\mathrm{C}_{2} \mathrm{H}_{4}$ and $\mathrm{H}_{2}$ are directly injected from the fuel surface into the combustion chamber. It is worth noting that, despite this relevant simplification, the following GSI approach retains its validity as the decomposition of the entrained droplets and the corresponding heat absorption take place away from the fuel interface and inside the combustion chamber where plenty of thermal energy is available. Therefore, the overall surface mass balance becomes:

$$
\dot{m}_{\mathrm{ent}}=\rho_{s} \dot{r}=(\rho v)_{w} \quad(\text { Mass })
$$

where $\rho$ and $v$ are the wall density and the normal-to-wall velocity in the gas phase due to gaseous fuel products injection because of grain regression. In the assumption that the entrained droplets are directly injected from the fuel wall in the gaseous phase, the species mass balance becomes analogous to that of a pyrolyzing fuel (see paragraph 2.1.1):

$$
\rho D_{i m} \frac{\partial y_{i}}{\partial \eta}+\dot{\omega}_{i}=(\rho v)_{w} y_{i}, \quad i=1,2, \ldots, N \quad \text { (Species) }
$$

where $\dot{\omega}_{i}$ is nonzero only for $\mathrm{C}_{2} \mathrm{H}_{4}$ and $\mathrm{H}_{2}$. Finally, the energy balance at the surface is: 


$$
\underbrace{k \frac{\partial T}{\partial \eta}}_{\text {convection }}=\underbrace{\dot{q}_{\text {cond }}^{s s}}_{\text {conduction }} \text { (Energy). }
$$

Equation (9) differs substantially from Eq. (5) since it does not include the chemical contribution. The entrainment process, in fact, is a mechanical phenomena related to the shear stress at the gas/melt-layer interface and, therefore, there is no chemical energy associated with this kind of fuel mass removal. Again, the radiation contributions do not appear in the energy balance as they have not been modeled in the present study.

Concerning the energy transfer into the fuel grain (melt-layer and solid), as done for the pyrolyzing fuel, it is assumed that heat conduction is dominant in the direction normal to the grain surface. The heat absorbed by the melted fuel flowing from the melt-layer/solid to the gas/melt-layer interface is accounted for through the liquid velocity in the melt-layer, $v_{l}$. As far as the energy transfer in the melt-layer is concerned, the melted fuel flow in the direction parallel to the fuel grain is neglected here. In a moving local coordinate system tied to the receding gas/melt-layer interface $\left(\dot{r}_{l}\right)$ and melt-layer/solid interface $\left(\dot{r}_{s}\right)$, the general 1D form of the in-depth energy balance (assuming constant material properties) is:

$$
\begin{aligned}
\frac{\partial T_{l}}{\partial t} & =\alpha_{l} \frac{\partial^{2} T_{l}}{\partial \eta^{2}}-\dot{r}_{l} \frac{\partial T_{l}}{\partial \eta}-v_{l} \frac{\partial T_{l}}{\partial \eta} \quad \text { (Energy in the melt-layer) } \\
\frac{\partial T_{s}}{\partial t} & =\alpha_{s} \frac{\partial^{2} T_{s}}{\partial \eta^{2}}-\dot{r}_{s} \frac{\partial T_{s}}{\partial \eta} \quad \text { (Energy in the solid fuel layer). }
\end{aligned}
$$

If the steady-state condition is assumed $\left(\dot{r}=\dot{r}_{l}=\dot{r}_{s}\right)$, then the stationary form of the in-depth energy balance is:

$$
\begin{aligned}
\alpha_{l} \frac{\partial^{2} T_{l}}{\partial \eta^{2}} & =\frac{\rho_{s}}{\rho_{l}} \dot{r} \frac{\partial T_{l}}{\partial \eta} \quad \text { (Stationary energy in the melt-layer); } \\
\alpha_{s} \frac{\partial^{2} T_{s}}{\partial \eta^{2}} & =\dot{r} \frac{\partial T_{s}}{\partial \eta} \quad \text { (Stationary energy in the solid fuel layer). }
\end{aligned}
$$

The terms $\alpha_{l}=k_{l} /\left(\rho_{l} c_{l}\right)$ and $\alpha_{s}=k_{s} /\left(\rho_{s} c_{s}\right)$ are the liquid and solid fuel grain thermal diffusivities, respectively, and $T_{l}$ and $T_{s}$ are the grain liquid and solid local temperatures, respectively. Integrating Eqs. (10) and (11) within the liquid layer and solid layer thicknesses, respectively, and considering the surface energy balance at the melt-layer/solid interface, the steady-state conduction term $\dot{q}_{\text {cond }}^{s s}$ can be expressed as:

$$
\dot{q}_{\mathrm{cond}}^{s s}=\dot{m}_{\mathrm{ent}} c_{l}\left(T_{w}-T_{m}\right)+\dot{m}_{\mathrm{ent}} \Delta h_{\mathrm{melt}}+\dot{m}_{\mathrm{ent}} c_{s}\left(T_{m}-T_{i}\right)
$$


Table 3 Paraffin wax $\left(\mathrm{C}_{32} \mathrm{H}_{66}\right)$ properties [3]

\begin{tabular}{cccc}
\hline $\begin{array}{c}\text { Density } \rho_{s}, \\
\mathrm{~kg} / \mathrm{m}^{3}\end{array}$ & $\begin{array}{c}\text { Specific heat } c_{s}, \\
\mathrm{~J} /(\mathrm{kg} \cdot \mathrm{K})\end{array}$ & $\begin{array}{c}\text { Thermal conductivity } k_{s}, \\
\mathrm{~W} /(\mathrm{m} \cdot \mathrm{K})\end{array}$ & $\begin{array}{c}\text { Melting enthalpy, } \\
\mathrm{MJ} / \mathrm{kg}\end{array}$ \\
\hline 920 & 2900 & 0.325 & 0.17 \\
\hline
\end{tabular}

where $c_{l}$ and $c_{s}$ indicate the melt-layer and solid fuel heat capacities, respectively. The terms $\Delta h_{\text {melt }}$ and $T_{m}$ represent the paraffin wax melting enthalpy and melting temperature, respectively. The term $T_{w}$ is the melt-layer temperature at the melt-layer/gas interface and $T_{i}$ is the solid fuel initial temperature.

The rate of melt-layer entrainment at the surface, $\dot{m}_{\text {ent }}$ appearing in Eqs. (7) and (12), has to be estimated on the basis of a fuel entrainment model, which is typically based on semiempirical correlations. In this work, however, the attention is rather focused on the relationship between the surface temperature and the entrainment mass flux so that a fuel entrainment model is not used. The entrainment mass flux, hence, is determined from the surface energy balance, Eq. (9), coupled with the steady-state heat conduction inside the fuel melt-layer and solid layer, Eq. (12), assuming an isothermal wall condition. From the knowledge of the gas/melt-layer interface

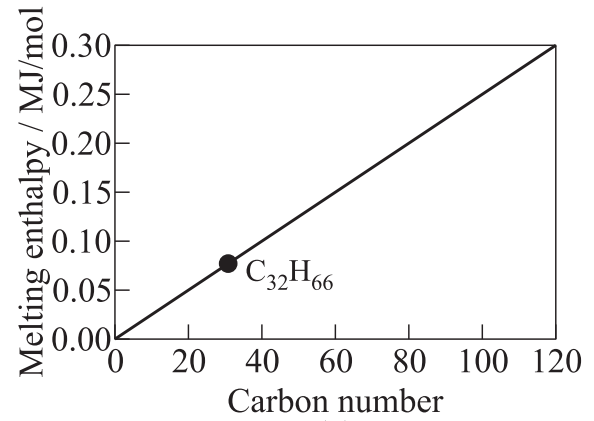

(a)

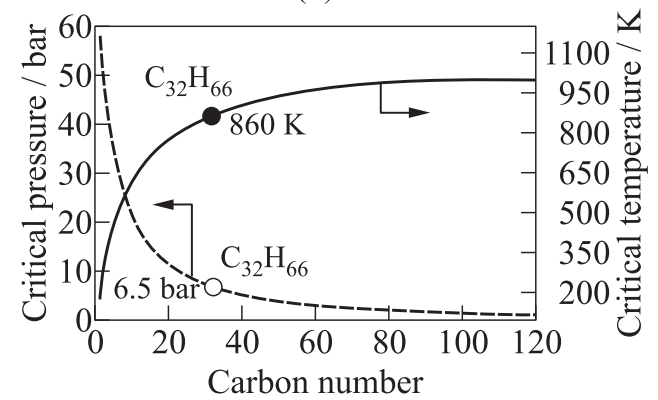

(b)

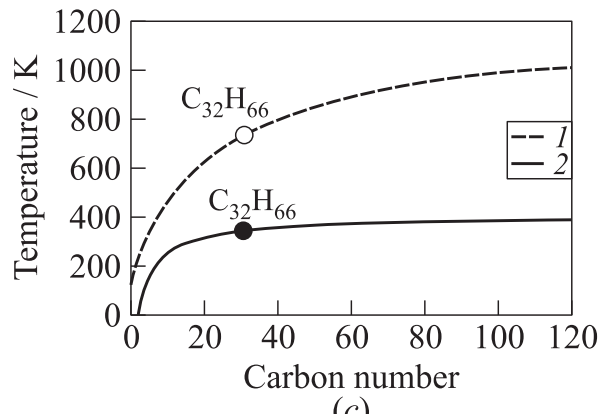

(c)

Figure 1 Paraffin wax properties as a function of carbon number: $(a)$ melting enthalpy [3]; $(b)$ critical values $[26,27]$; and $(c)$ normal boiling $(1)$ and melting (2) temperatures [26,27] 


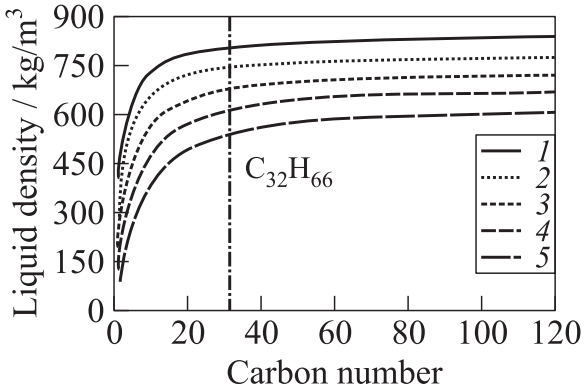

(a)

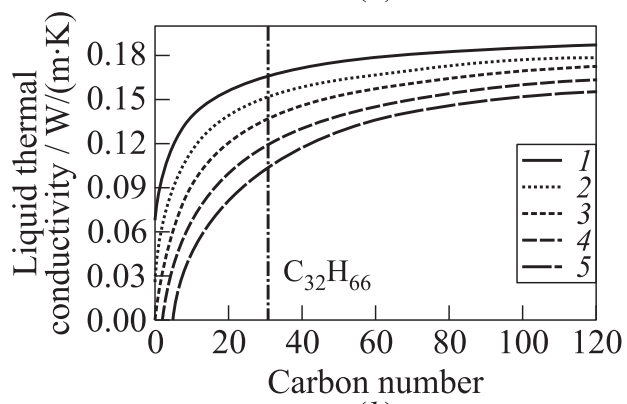

(b)

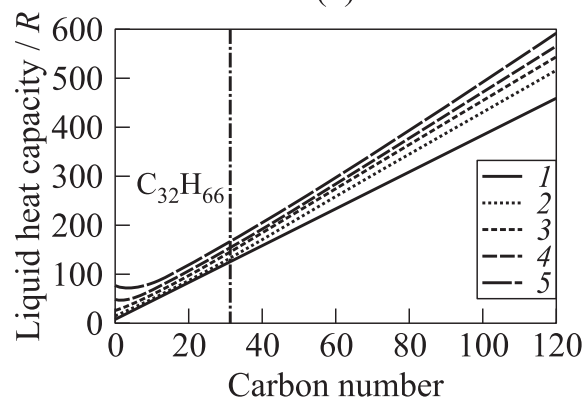

(c)

Figure 2 Liquid paraffin wax properties as functions of carbon number: $(a)$ density [26,27]; (b) thermal conductivity $[26,28]$; (c) heat capacity $[26,28] ; 1-T=300 \mathrm{~K} ; 2-400 ; 3-500$; $4-600$; and $5-T=700 \mathrm{~K}$ temperature, which is, in turn, related to the melt-layer thickness, the entrainment mass flux can be obtained solving Eqs. (9) and (12) iteratively coupled with Eqs. (7) and (8), which are needed to solve for the gas surface chemical composition.

In Table 3, the paraffin wax properties (at solid state) used for the simulations are listed. The heat conducted in the solid grain is modeled according to Eq. (12) where a constant specific heat has been assumed for the solid paraffin. The solid wax thermal conductivity $k_{s}$ is also assumed constant with temperature. A value of $0.17 \mathrm{MJ} / \mathrm{kg}$ has been assumed for the melting enthalpy of $\mathrm{C}_{32} \mathrm{H}_{66}$, shown in Fig. $1 a$, as performed in [3]. The critical pressure and temperature and the melting and normal boiling temperatures as a function of carbon number are shown in Figs. $1 b$ and $1 c$ and have been estimated using the asymptotic behavior correlation (ABC) method as discussed in [26-28]. Finally, the liquid wax density, thermal conductivity, and heat capacity as functions of temperature and carbon number are shown in Fig. 2 and have been estimated using the ABC method [26-28]. The melt-layer properties are assumed constant over

the melt-layer thickness for simplicity and have been evaluated at the average temperature between the gas/melt-layer interface temperature (surface temperature) and the melt-layer/solid interface temperature (melting temperature). As shown in Fig. 1b, the critical pressure of $\mathrm{C}_{32} \mathrm{H}_{66}$ is 6.5 bar so that, as the computed chamber pressure for the analyzed conditions is always above this 
value, liquid $\mathrm{C}_{32} \mathrm{H}_{66}$ cannot evaporate or boil, being at a supercritical pressure. Also, as in the performed numerical simulations, the gas/melt-layer interface temperature is kept below the $\mathrm{C}_{32} \mathrm{H}_{66}$ critical temperature $(860 \mathrm{~K})$, a supercritical liquid layer cannot be formed. Consequently, the only additional mass transfer mechanism other than that of entrainment is the pyrolysis of the melt-layer. In the current analysis, the pyrolysis of the melt-layer is neglected and the the gas/melt-layer interface temperature is confined between the melting temperature $(340 \mathrm{~K})$, which corresponds to a null melt-layer thickness, and the normal boiling temperature $(740 \mathrm{~K})$ of $\mathrm{C}_{32} \mathrm{H}_{66}$, which corresponds to the maximum melt-layer thickness. Melt-layer pyrolysis analysis for $\mathrm{C}_{32} \mathrm{H}_{66}$ has been performed in [3] showing that, for surface temperatures lower than $\approx 700 \mathrm{~K}$, the pyrolysis fuel regression rate becomes negligibly small. Therefore, for the current analyzed conditions, the assumption that the dominant mass removal mechanism is due to the entrainment phenomena is justified.

\subsection{Gas Phase Reactions}

Finite-rate gas phase reactions are modeled by global reaction mechanisms, because detailed chemical kinetics mechanisms would include many species and would be, on the one hand, computationally heavy and, on the other hand, beyond the scope of the present study, whose aim is to focus on GSI. Therefore, finite-rate gas phase reactions are modeled by a simplified two-step global reaction mechanism which involves two global reaction steps. In case of pyrolyzing fuels, such as HTPB, the first irreversible global reaction step is between $\mathrm{C}_{4} \mathrm{H}_{6}$, which is the HTPB pyrolysis product, and molecular oxygen to form $\mathrm{CO}$ and $\mathrm{H}_{2} \mathrm{O}$ and is considered first order in both fuel and oxidizer. The second reversible global step accounts for the formation of $\mathrm{CO}_{2}$ :

$$
\begin{aligned}
& \mathrm{C}_{4} \mathrm{H}_{6}+3 \mathrm{O}_{2} \Rightarrow 4 \mathrm{CO}+2 \mathrm{H}_{2} \mathrm{O}+\mathrm{H}_{2} ; \\
& \mathrm{CO}+0.5 \mathrm{O}_{2} \Leftrightarrow \mathrm{CO}_{2} .
\end{aligned}
$$

The resulting rates of production and destruction of species are:

$$
\begin{aligned}
\dot{w}_{\mathrm{C}_{4} \mathrm{H}_{6}} & =-M_{\mathrm{C}_{4} \mathrm{H}_{6}} k_{f_{1}}\left[\mathrm{C}_{4} \mathrm{H}_{6}\right]\left[\mathrm{O}_{2}\right] \\
\dot{w}_{\mathrm{O}_{2}} & =M_{\mathrm{O}_{2}}\left\{-3 k_{f_{1}}\left[\mathrm{C}_{4} \mathrm{H}_{6}\right]\left[\mathrm{O}_{2}\right]\right. \\
& \left.-0.5\left(k_{f_{2}}[\mathrm{CO}]\left[\mathrm{H}_{2} \mathrm{O}\right]^{0.5}\left[\mathrm{O}_{2}\right]^{0.25}-k_{b_{2}}\left[\mathrm{CO}_{2}\right]\left[\mathrm{H}_{2} \mathrm{O}\right]^{0.5}\left[\mathrm{O}_{2}\right]^{-0.25}\right)\right\} ; \\
\dot{w}_{\mathrm{CO}} & =M_{\mathrm{CO}}\left\{4 k_{f_{1}}\left[\mathrm{C}_{4} \mathrm{H}_{6}\right]\left[\mathrm{O}_{2}\right]\right. \\
& \left.-\left(k_{f_{2}}[\mathrm{CO}]\left[\mathrm{H}_{2} \mathrm{O}\right]^{0.5}\left[\mathrm{O}_{2}\right]^{0.25}-k_{b_{2}}\left[\mathrm{CO}_{2}\right]\left[\mathrm{H}_{2} \mathrm{O}\right]^{0.5}\left[\mathrm{O}_{2}\right]^{-0.25}\right)\right\} ;
\end{aligned}
$$


Table 4 Reaction rate constants for reactions (13) and (14)

\begin{tabular}{cccc}
\hline Reaction rate & $A$ & $\mathrm{n}$ & $E_{a} / R, \mathrm{~K}$ \\
\hline$k_{f_{1}}[29]$ & $4.9486 \cdot 10^{9}$ & 0.0 & 15200 \\
$k_{f_{2}}[30]$ & $2.2400 \cdot 10^{6}$ & 0.0 & 5032.7 \\
$k_{b_{2}}[30]$ & $1.1000 \cdot 10^{13}$ & -0.97 & 39456.5 \\
\hline
\end{tabular}

$$
\begin{aligned}
\dot{w}_{\mathrm{H}_{2} \mathrm{O}} & =2 M_{\mathrm{H}_{2} \mathrm{O}} k_{f_{1}}\left[\mathrm{C}_{4} \mathrm{H}_{6}\right]\left[\mathrm{O}_{2}\right] ; \\
\dot{w}_{\mathrm{H}_{2}} & =M_{\mathrm{H}_{2}} k_{f_{1}}\left[\mathrm{C}_{4} \mathrm{H}_{6}\right]\left[\mathrm{O}_{2}\right] ; \\
\dot{w}_{\mathrm{CO}_{2}} & =M_{\mathrm{CO}_{2}}\left(k_{f_{2}}[\mathrm{CO}]\left[\mathrm{H}_{2} \mathrm{O}\right]^{0.5}\left[\mathrm{O}_{2}\right]^{0.25}-k_{b_{2}}\left[\mathrm{CO}_{2}\right]\left[\mathrm{H}_{2} \mathrm{O}\right]^{0.5}\left[\mathrm{O}_{2}\right]^{-0.25}\right) .
\end{aligned}
$$

The forward and backward reaction rates $k_{f}$ and $k_{b}$ for the two reactions are expressed as Arrhenius functions in the form $k=A T^{n} \exp \left(-E_{a} /(R T)\right)$, and the values of the constants used in this study are tabulated in Table 4 . The first global step reaction rate is taken from [29] and the second step is taken from [30], which is a modified version of the one used in [21,29] to account for oxy-fuel combustion conditions.

When paraffin-based liquefying fuels are considered, paraffin wax $\left(\mathrm{C}_{32} \mathrm{H}_{66}\right)$ is assumed to decompose/gasify into $\mathrm{C}_{2} \mathrm{H}_{4}$ and molecular hydrogen through the reaction $\mathrm{C}_{32} \mathrm{H}_{66} \Rightarrow \mathrm{H}_{2}+16 \mathrm{C}_{2} \mathrm{H}_{4}$. As a single-phase approach is used in this study, the pyrolysis/vaporization of the entrained liquid droplets is not modeled and gaseous $\mathrm{C}_{2} \mathrm{H}_{4}$ and $\mathrm{H}_{2}$ (assumed as inert) are directly injected from the fuel surface into the combustion chamber.

The simplified two-step global reaction mechanism for $\mathrm{C}_{2} \mathrm{H}_{4}$ is:

$$
\begin{aligned}
\mathrm{C}_{2} \mathrm{H}_{4}+1.5 \mathrm{O}_{2} & \Rightarrow 2 \mathrm{CO}+\mathrm{H}_{2} \mathrm{O}+\mathrm{H}_{2} ; \\
\mathrm{CO}+0.5 \mathrm{O}_{2} & \Leftrightarrow \mathrm{CO}_{2} .
\end{aligned}
$$

The resulting rates of production and destruction of species are:

$$
\begin{aligned}
\dot{w}_{\mathrm{C}_{2} \mathrm{H}_{4}}= & -M_{\mathrm{C}_{2} \mathrm{H}_{4}} k_{f_{1}}\left[\mathrm{C}_{2} \mathrm{H}_{4}\right]\left[\mathrm{O}_{2}\right] ; \\
\dot{w}_{\mathrm{O}_{2}}= & M_{\mathrm{O}_{2}}\left\{-1.5 k_{f_{1}}\left[\mathrm{C}_{2} \mathrm{H}_{4}\right]\left[\mathrm{O}_{2}\right]\right. \\
& \left.-0.5\left(k_{f_{2}}[\mathrm{CO}]\left[\mathrm{H}_{2} \mathrm{O}\right]^{0.5}\left[\mathrm{O}_{2}\right]^{0.25}-k_{b_{2}}\left[\mathrm{CO}_{2}\right]\left[\mathrm{H}_{2} \mathrm{O}\right]^{0.5}\left[\mathrm{O}_{2}\right]^{-0.25}\right)\right\} ; \\
\dot{w}_{\mathrm{CO}}= & M_{\mathrm{CO}}\left\{2 k_{f_{1}}\left[\mathrm{C}_{2} \mathrm{H}_{4}\right]\left[\mathrm{O}_{2}\right]\right. \\
& \left.\quad-\left(k_{f_{2}}[\mathrm{CO}]\left[\mathrm{H}_{2} \mathrm{O}\right]^{0.5}\left[\mathrm{O}_{2}\right]^{0.25}-k_{b_{2}}\left[\mathrm{CO}_{2}\right]\left[\mathrm{H}_{2} \mathrm{O}\right]^{0.5}\left[\mathrm{O}_{2}\right]^{-0.25}\right)\right\} ; \\
\dot{w}_{\mathrm{H}_{2} \mathrm{O}}= & M_{\mathrm{H}_{2} \mathrm{O}} k_{f_{1}}\left[\mathrm{C}_{2} \mathrm{H}_{4}\right]\left[\mathrm{O}_{2}\right] ;
\end{aligned}
$$




$$
\begin{aligned}
\dot{w}_{\mathrm{H}_{2}} & =M_{\mathrm{H}_{2}} k_{f_{1}}\left[\mathrm{C}_{2} \mathrm{H}_{4}\right]\left[\mathrm{O}_{2}\right] \\
\dot{w}_{\mathrm{CO}_{2}} & =M_{\mathrm{CO}_{2}}\left(k_{f_{2}}[\mathrm{CO}]\left[\mathrm{H}_{2} \mathrm{O}\right]^{0.5}\left[\mathrm{O}_{2}\right]^{0.25}-k_{b_{2}}\left[\mathrm{CO}_{2}\right]\left[\mathrm{H}_{2} \mathrm{O}\right]^{0.5}\left[\mathrm{O}_{2}\right]^{-0.25}\right) .
\end{aligned}
$$

The forward and backward reaction rates $k_{f}$ and $k_{b}$ for the two reactions are expressed as Arrhenius functions in the form $k=A T^{n} \exp \left(-E_{a} /(R T)\right)$ and the values of the constants used in this study are tabulated in Table 4. In particular, the forward rate for the first irreversible global reaction step is assumed identical for both $\mathrm{C}_{2} \mathrm{H}_{4}$ and $\mathrm{C}_{4} \mathrm{H}_{6}$.

\section{TEST CASE DESCRIPTION}

The results have been obtained on a typical cylindrical port geometry with a prechamber and an aft-mixing chamber whose dimensions and flow conditions are shown in Fig. 3. The computational domain refers to a simplified geometrical
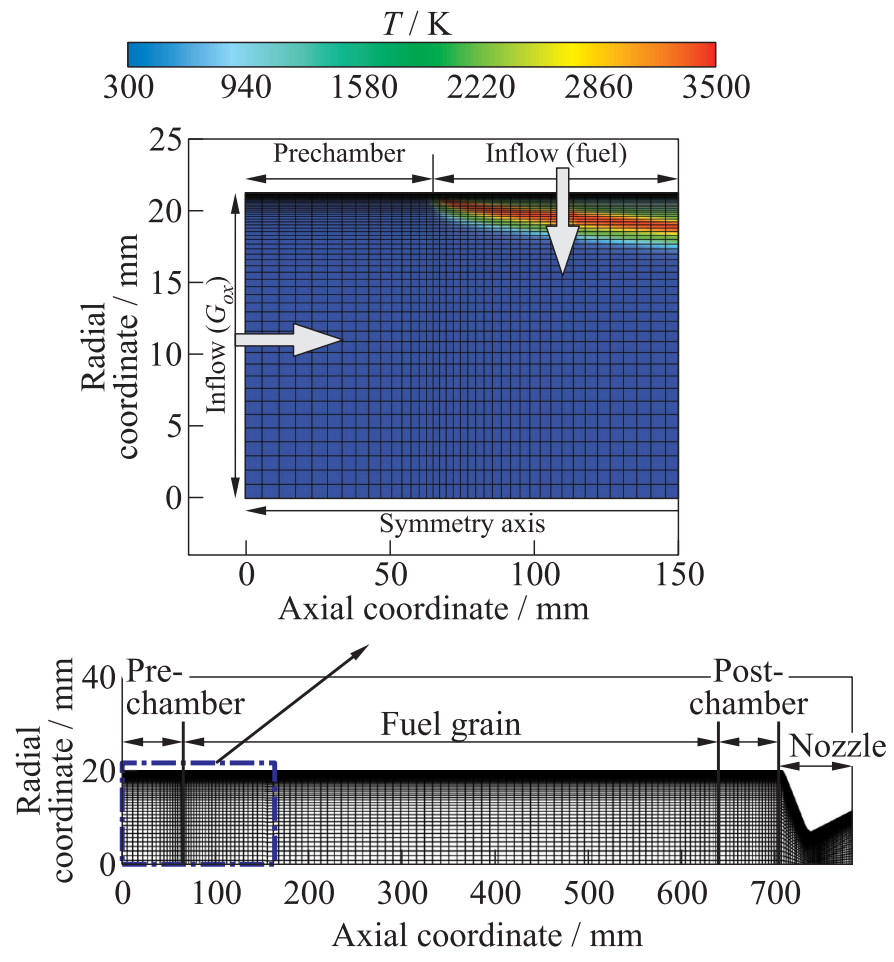

Figure 3 Computational domain: numerical grid (not to scale) and boundary conditions 
representation of a real hybrid rocket chamber geometry where the prechamber, fuel grain, and postchamber have been schematized with constant cross section. The length of the domain portion corresponding to the fuel grain is $574 \mathrm{~mm}$, the port diameter is equal to $42 \mathrm{~mm}$, and the throat diameter is equal to $16 \mathrm{~mm}$. Gaseous oxygen is injected throughout the entire fuel port at a total temperature of $300 \mathrm{~K}$ and at different mass fluxes. The fuel gaseous mixture which is injected from the wall in a gaseous oxygen stream is assumed to be $\mathrm{C}_{4} \mathrm{H}_{6}$ in case of HTPB and a mixture of $\mathrm{C}_{2} \mathrm{H}_{4}$ and $\mathrm{H}_{2}$ in case of paraffin wax $\left(\mathrm{C}_{32} \mathrm{H}_{66}\right)$.

\section{RESULTS AND DISCUSSION}

The results presented here are restricted to single-phase system; therefore, in case of liquefying fuels, the entrained fuel liquid droplets are not modeled and the fuel is directly injected in a gaseous state from the gas/melt-layer interface. This is an approximation of the real phenomena as the liquid droplets do not vaporize directly at the surface but are rather transported inside the flowfield and, hence, they should not contribute to the blockage effect, which is typical of pyrolyzing fuels. With a single-phase approach, however, the gaseous injected fuel is contributing to the blockage effect. This effect, which reduces the heat transfer to the fuel grain, is possibly counteracted by the absence of the endothermic cracking reaction and the associated heat of cracking. All the computations presented here are two-dimensional (axisymmetric) and at the steady-state condition. For each value of oxygen mass flux enforced, the CFD simulation provides the fuel mass flux (from the surface mass and energy balance) and the chamber pressure level as a consequence of the choked condition at the nozzle throat. Therefore, the chamber pressure level attained in the motor depends on the mixing and combustion process and also on the interaction with the pyrolyzing (HTPB) or liquefying (paraffin wax) fuel. In this work, the effect of the fuel port variation is not analyzed, so that all simulations have been performed at a fixed port diameter as shown in Fig. 3. The following results are obtained for paraffin wax $\mathrm{C}_{32} \mathrm{H}_{66}$ at different gas/melt-layer interface temperatures and for various oxygen mass fluxes and are compared with those obtained using HTPB at the same operating conditions.

\subsection{Role of Surface Temperature}

The role of the gas/melt-layer interface temperature on entrainment mass flux is analyzed on a reference configuration with an oxygen mass flux of $94 \mathrm{~kg} /\left(\mathrm{m}^{2} \mathrm{~s}\right)$ for $\mathrm{C}_{32} \mathrm{H}_{66}$ paraffin wax. A reference simulation using HTPB is also performed. The gas/melt-layer interface temperature is assigned in the computation and assumed constant throughout the entire 574-millimeter fuel grain length. It is varied from 
the melting temperature $(340 \mathrm{~K})$ to the normal boiling temperature $(740 \mathrm{~K})$ with constant intervals of $100 \mathrm{~K}$. In case of HTPB, the surface temperature is not imposed at the fuel interface but it is calculated solving the surface energy balance, Eq. (5), and, hence, it is varying along the fuel grain length typically ranging from 750 to $850 \mathrm{~K}$.

Figures 4 and 5 shows the motor internal ballistics as functions of gas/meltlayer interface temperature at constant port area and oxygen mass flux. As seen, the gas/melt-layer interface temperature is significantly affecting the flowfield with a much higher production of the gaseous fuel (which is predominantly $\mathrm{C}_{2} \mathrm{H}_{4}$ ) at the lower interface temperatures.

Figure $6 a$ shows the typical regression behavior as predicted by classical boundary-layer theory with an initial regression rate decrease due to the boundary-layer growth and, then, an increase due to the mass and heat addition. The highest fuel regression rate shown in Fig. $6 a$ is obtained at the lowest interface temperature (i.e., the wax melting temperature) due to the increase of the convective heating from the hot gases and the decrease of the conduction inside the fuel grain (see Eqs. (9) and (12)). Due to the higher regression rate of paraffin wax with respect to HTPB, the flame is shifted away (see Fig. 4) from the surface by the gaseous fuel injected into the fuel port, the chamber pressure is increased (see Figs. 5 and $6 b$ ), and more oxygen is consumed (see Fig. 5). The peak flame temperature and the axial velocity inside the chamber, on the other hand, are not significantly affected by the increasing wax regression rate. As shown in Fig. $6 a$, as the interface temperature approaches the maximum temperature (normal boiling temperature), the regression rate decreases and becomes similar to that of HTPB at the same port area and oxygen mass flux. At the melting temperature, the wax regression rate is more than 4 times higher than HTPB while at the normal boiling temperature, the wax regression rate is only 1.3 times that of HTPB.

Figure 7 shows the paraffin wax spatially averaged regression rate as a function of gas/melt-layer interface temperature for different oxygen mass fluxes (ranging from 47 to $282 \mathrm{~kg} /\left(\mathrm{m}^{2} \mathrm{~s}\right)$ ). As shown in Fig. $7 b$, the paraffin wax regression rate variation with the gas/melt-layer interface temperature is very well matched by an inverse power law of the form $\dot{r}=a / T_{w}^{n}$ with the index $n$ varying from 1.45 to 1.6. The paraffin wax regression rate increase with decreasing gas/melt-layer interface temperature (see Fig. $7 a$ ) is following an inverse power law as the decrease of the interface temperature produces an increase of the convective heat flux from the combustion gases and a concurrent decrease of the conductive heat flux into the propellant grain and both contribute to increase the fuel regression rate. Figure $7 b$ clearly shows that a significantly higher regression rate for paraffin wax with respect to HTPB (from 3 to more than 4 times) can only be obtained when the interface temperature is not too far from the wax melting temperature. The results also show an increase of the paraffin wax regression rate enhancement with respect to HTPB at increasing oxygen mass flux. 
Temperature / K
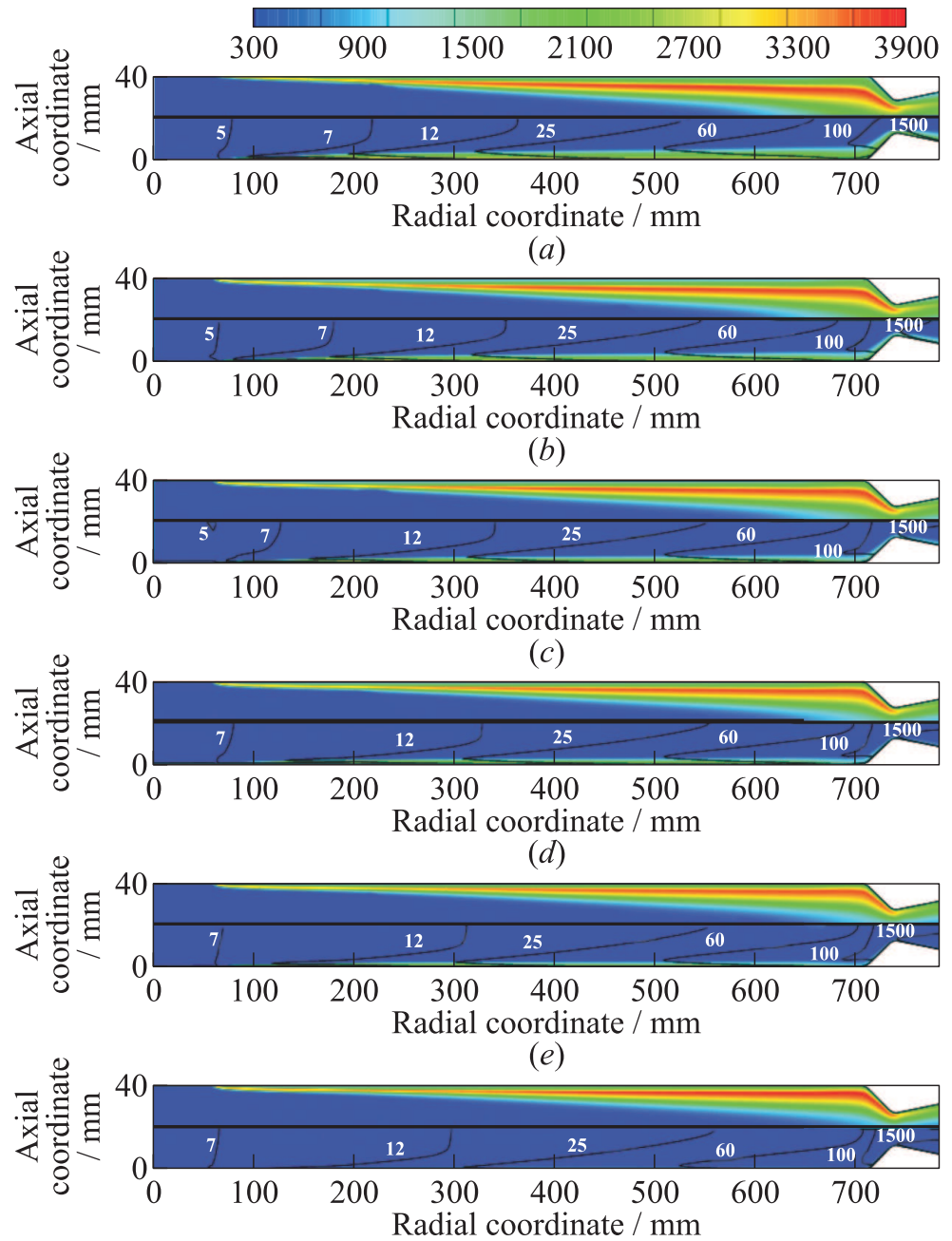

$(f)$

Fuel mass fraction

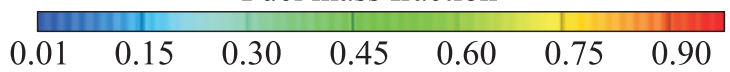

Figure 4 Temperature (up) and fuel concentration (down) fields for $\mathrm{C}_{32} \mathrm{H}_{66}$ paraffin wax with axial velocity isocontours at a constant mass flux $G_{\mathrm{ox}}=94 \mathrm{~kg} /\left(\mathrm{m}^{2} \mathrm{~s}\right)$ and different gas/melt-layer interface temperatures: (a) $340 \mathrm{~K} ;(b) 440 ;(c)$ 540; (d) 640; and $(e) 740 \mathrm{~K}$. The HTPB results $(f)$ are shown as a reference 


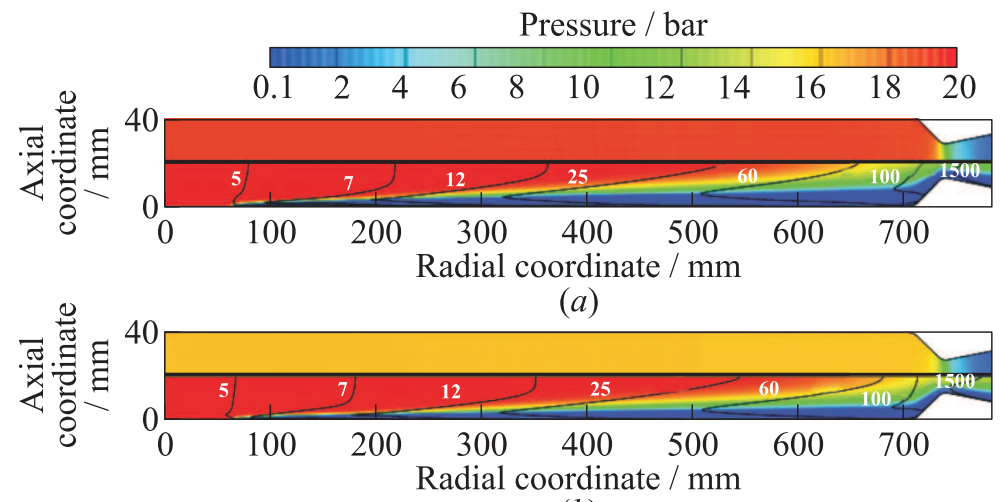

(b)
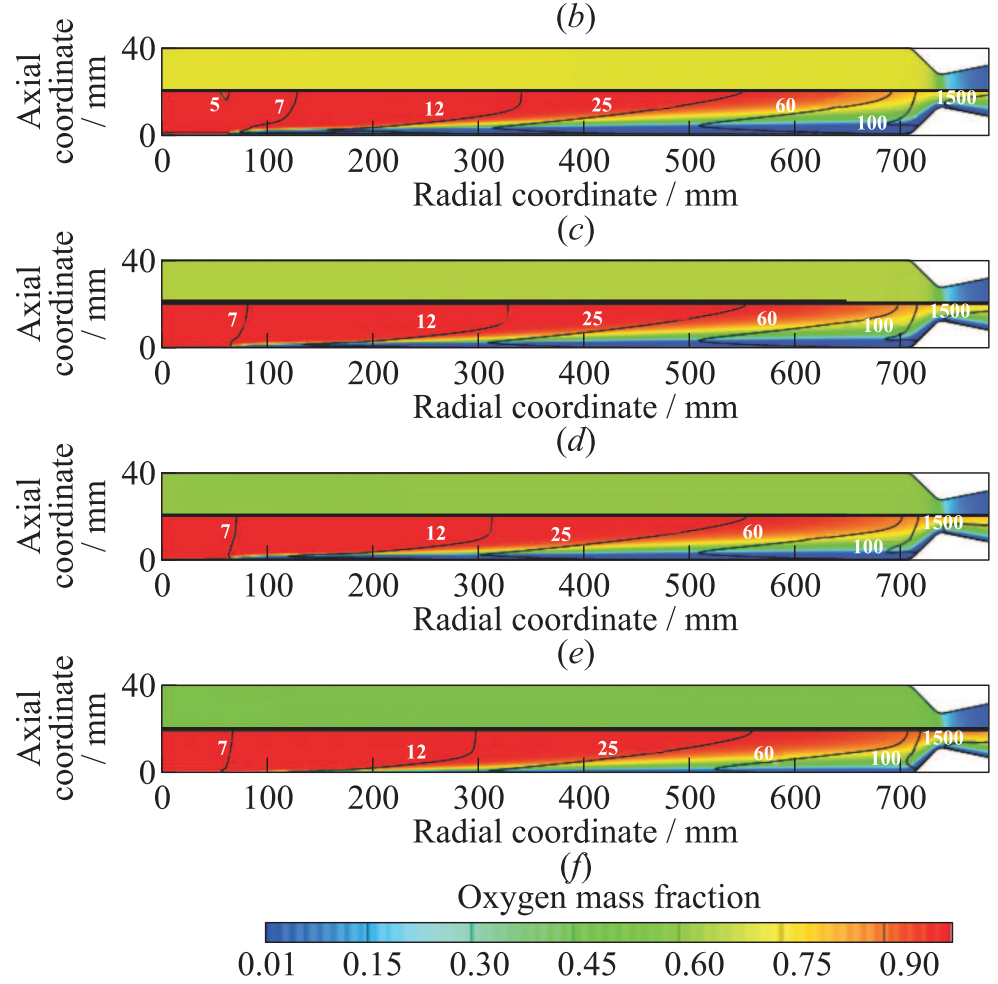

Figure 5 Pressure (up) and oxygen concentration (down) fields for $\mathrm{C}_{32} \mathrm{H}_{66}$ paraffin wax with axial velocity isocontours at a constant mass flux $G_{\mathrm{ox}}=94 \mathrm{~kg} /\left(\mathrm{m}^{2} \mathrm{~s}\right)$ and different gas/melt-layer interface temperatures: (a) $340 \mathrm{~K} ;(b) 440 ;(c)$ 540; (d) 640; and $(e) 740 \mathrm{~K}$. The HTPB results $(f)$ are shown as a reference 


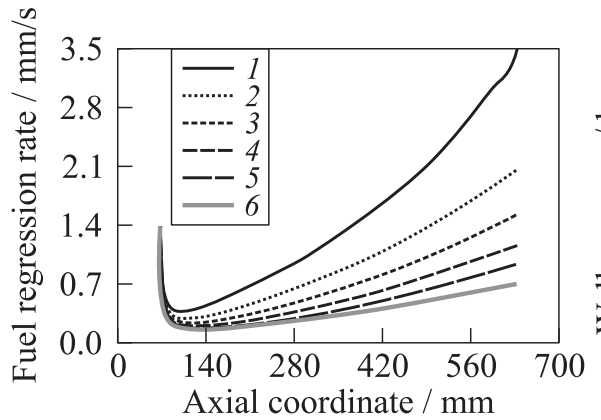

(a)

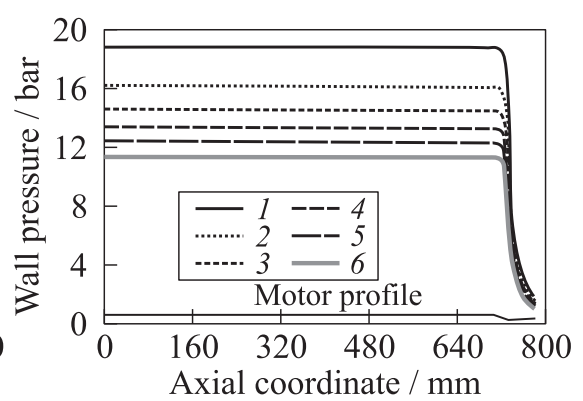

(b)

Figure 6 Fuel regression rate $(a)$ and wall pressure $(b)$ axial distributions for $\mathrm{C}_{32} \mathrm{H}_{66}$ paraffin wax at varying gas/melt-layer interface temperatures for a constant mass flux $G_{\text {ox }}=94 \mathrm{~kg} /\left(\mathrm{m}^{2} \mathrm{~s}\right): 1-340 \mathrm{~K} ; 2-440 ; 3-540 ; 4-640$; and $5-740 \mathrm{~K}$. The HTPB results (6) are shown as a reference

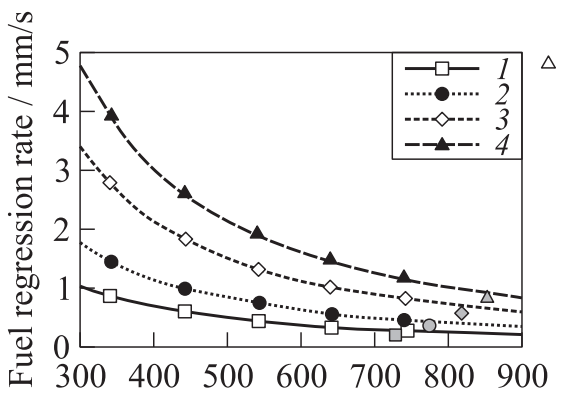

$\mathrm{Gas} /$ fuel interface temperature / K (a)

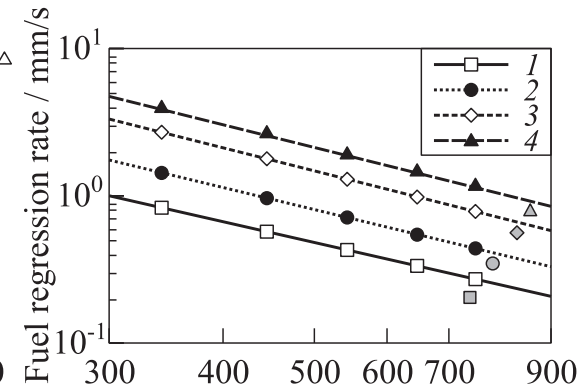

$\mathrm{Gas} /$ fuel interface temperature / K

(b)

Figure 7 Spatially averaged fuel regression rate as a function of gas/melt-layer interface temperature for paraffin wax at varying mass fluxes $G_{\text {ox }}: 1-47 \mathrm{~kg} /\left(\mathrm{m}^{2} \mathrm{~s}\right)$; $2-94 ; 3-188$; and $4-282 \mathrm{~kg} /\left(\mathrm{m}^{2} \mathrm{~s}\right)$. The HTPB results (grey symbols) are shown as a reference

At the lowest oxygen mass flux of $47 \mathrm{~kg} / \mathrm{m}^{2} \mathrm{~s}$, in fact, the paraffin wax regression rate at the melting temperature is 4 times than that of HTPB, while it increase up to 5 times at the maximum considered oxygen mass flux of $282 \mathrm{~kg} /\left(\mathrm{m}^{2} \mathrm{~s}\right)$.

\subsection{Role of Oxygen Mass Flux}

The role of the oxygen mass flux on the entrainment mass flux at different fixed gas/melt-layer interface temperatures is analyzed in Fig. 8. The results of Fig. $8 b$ show the typical regression rate power law relationship of the form $\dot{r}=a G_{\mathrm{ox}}^{n}$. The 


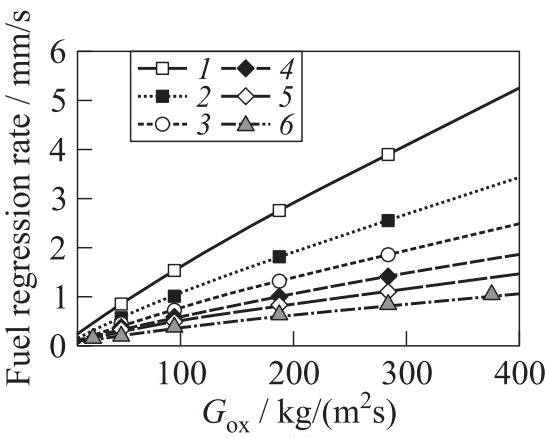

(a)

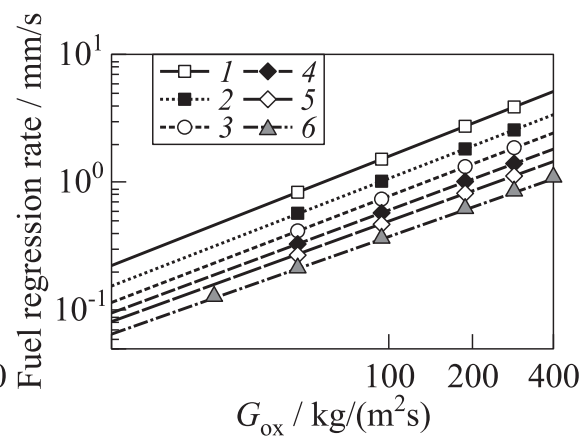

(b)

Figure 8 Spatially averaged fuel regression rate as a function of mass flux $G_{\text {ox }}$ for paraffin wax at varying gas/melt-layer interface temperatures: $1-342.15 \mathrm{~K} ; 2-$ $442.15 ; 3-542.15 ; 4-642.15$; and $5-742.15 \mathrm{~K}$. The HTPB results $(6)$ are shown as a reference

gas/melt-layer interface temperature is directly affecting the $a$ parameter while it is only slightly modifying the oxidizer flux exponent $n$, which remains close to a classical value in the range of 0.8 . At the boiling temperature, in fact, the oxidizer flux exponent is equal to 0.79 and it increases up to 0.86 at the melting temperature, hence showing a limited difference from the obtained HTPB value of 0.75. Most of the effect, in fact, is on the $a$ parameter which is increased by 2.4 times passing from the boiling temperature to the melting temperature. Therefore, the variation of the gas/melt-layer interface temperature, although significantly affecting the fuel regression rate, does not alter in a substantial way the regression behavior at varying oxygen mass flux as the oxidizer flux exponent remains rather constant and close to the value of HTPB. In conclusion, the paraffin wax regression rate enhancement with respect to HTPB is shown to be mostly affected by the gas/melt-layer interface temperature (and, hence, by the melt-layer thickness) and only partially influenced by the oxidizer mass flux, although a limited increase is also shown with increasing $G_{\text {ox }}$ due to a small increase of the oxidizer flux exponent.

\section{CONCLUDING REMARKS}

A CFD approach to the internal ballistics of a hybrid motor with integrated GSI modeling capabilities for pyrolyzing fuels has been extended to the case of liquefying fuels, such as paraffin wax. The fluid dynamic equations are the RANS equations with additional transport equations for chemical species and turbulence, which are coupled to simplified two-step global reaction mechanisms to model the combustion process inside the combustion chamber. The gas-phase 
equations are solved and coupled to the liquid/solid fuel phase using surface balances of mass and energy, which enable the determination of the fuel regression rate as a part of the flowfield solution. A test case represented by the combustion in a cylindrical single-port hybrid rocket burning gaseous oxygen has been simulated. The considered fuel is either HTPB or paraffin wax. In case of paraffin wax, simulations have been performed varying the gas/melt-layer interface temperature to analyze its role on the entrainment mass flux at different oxygen mass fluxes. Results have shown that the entrainment regression rate increases with decreasing interface temperature following an inverse power law. The obtained inverse power law is due to the increase of the convective heating from the hot gases and the concurrent decrease of the conductive heating inside the fuel grain at decreasing interface temperatures. The entrainment regression rate can reach levels up to 4-5 times higher than those of HTPB at the same operating conditions when the interface temperature is close to the melting temperature, i. e., the melt-layer thickness gets close to zero. Differently, at the highest considered interface temperature which is assumed equal to the normal boiling point temperature, the entrainment regression rate is not significantly higher with respect to HTPB. Finally, the role of the oxygen mass flux on the entrainment mass flux at different fixed gas/melt-layer interface temperatures has been analyzed showing that the oxidizer flux exponent of the typical regression rate power law relationship is not substantially altered when liquefying fuels are considered. The oxidizer flux exponent, in fact, is only slightly increasing with decreasing interface temperatures but still it remains close to a classical value in the range of 0.8 , as for HTPB. In conclusion, the paraffin wax regression rate enhancement with respect to HTPB is shown to be mostly affected by the gas/melt-layer interface temperature and, hence, by the melt-layer thickness, and only partially influenced by the oxidizer mass flux due to the limited increase of the oxidizer flux exponent.

This work represents the first step towards the modeling of the complex interaction between the combustion gases and a liquefying fuel in hybrid rocket engines but still many areas require a modeling effort to enhance the entrainment phenomena modeling. Future work will include an entrainment model in order to remove the assumption of a fixed interface gas/melt-layer interface temperature, a simplified two-phase treatment to describe the evolution of the entrainment liquid droplets inside the chamber, better combustion models, and the inclusion of radiation exchange between the gas and the fuel.

\section{REFERENCES}

1. Karabeyoglu, M. A., D. Altman, and B. J. Cantwell. 2002. Combustion of liquefying hybrid propellants: Part 1. General theory. J. Propulsion Power 18(3):610-620. doi: $10.2514 / 2.5975$. 
2. Karabeyoglu, M. A., and B. J. Cantwell. 2002. Combustion of liquefying hybrid propellants: Part 2. Stability of liquid films. J. Propulsion Power 18(3):621-630. doi: $10.2514 / 2.5976$.

3. Karabeyoglu, M. A., B. J. Cantwell, and J. Stevens. 2005. Evaluation of homologous series of normal-alkanes as hybrid rocket fuels. AIAA Paper No. 2005-3908. doi: 10.2514/6.2005-3908.

4. Funami, Y., V. Novozhilov, I. Nakagawa, and T. Shimada. 2010. Regression modeling of paraffin-based hybrid rocket fuels for internal ballistics simulation. AIAA Paper No. 2012-6873. doi: 10.2514/6.2010-6873.

5. Barato, F., N. Bellomo, M. Lazzarin, F. Moretto, A. Bettella, and D. Pavarin. 2012. Numerical modeling of paraffin-based fuels behavior. AIAA Paper No. 2012-3750. doi: 10.2514/6.2012-3750.

6. Bellomo, N., M. Lazzarin, F. Barato, A. Bettella, D. Pavarin, and M. Grosse. 2014. Investigation of effect of diaphragms on the efficiency of hybrid rockets. J. Propul. Power 30(1):175-185. doi: 10.2514/1.B34908.

7. Karabeyoglu, A., G. Zilliac, B. J. Cantwell, S. Dezilwa, and P. Castellucci. 2004. Scale-up tests of high regression rate paraffin-based hybrid rocket fuels. J. Propul. Power 20(6):1037-1045.

8. Galfetti, L., L. Merotto, M. Boiocchi, F. Maggi, and L. De Luca. 2011. Ballistic and rheological characterization of paraffin-based fuels for hybrid rocket propulsion. AIAA Paper No. 2011-5680. doi: 10.2514/6.2011-5680.

9. Nakagawa, I., and S. Nikone. 2011. Study on the regression rate of paraffin-based hybrid rocket fuels. J. Propul. Power 27(6):1276-1279. doi: 10.2514/1.B34206.

10. Bellomo, N., F. Barato, M. Faenza, M. Lazzarin, A. Bettella, and D. Pavarin. 2013. Numerical and experimental investigation of unidirectional vortex injection in hybrid rocket engines. J. Propul. Power 29(5):1097-1113. doi: 10.2514/1.B34506.

11. Scaramuzzino, F., C. Carmicino, G. Festa, A. Russo Sorge, and A. Viviani. 2013. Fuel regression-rate characterization on a lab-scale hybrid rocket burning $\mathrm{N}_{2} \mathrm{O}$ and paraffin-based propellants. AIAA Paper No. 2013-4039. doi: 10.2514/6.2013-4039.

12. Kobald, M., C. Schmierer, H. Ciezki, S. Schlechtriem, E. Toson, and L. De Luca. 2014. Evaluation of paraffin-based fuels for hybrid rocket engines. AIAA Paper No. 2014-3646. doi: 10.2514/6.2014-3646.

13. Bianchi, D., A. Urbano, B. Betti, and F. Nasuti. 2013. CFD analysis of hybrid rocket flowfields including fuel pyrolysis and nozzle erosion. AIAA Paper No. 20133637. doi: 10.2514/6.2013-3637.

14. Bianchi, D., B. Betti, F. Nasuti, and C. Carmicino. 2015. Simulation of gaseous oxygen/hydroxyl-terminated polybutadiene hybrid rocket flowfields and comparison with experiments. J. Propul. Power 31(3):919-929. doi: 10.2514/1.B35587.

15. Bianchi, D., B. Betti, F. Nasuti, C. Carmicino, and A. Russo Sorge. 2014. Numerical modeling of GOx/HTPB hybrid rocket flowfields and comparison with experiments. AIAA Paper No. 2014-3545. doi: 10.2514/6.2014-3545.

16. Betti, B., F. Nasuti, and E. Martelli. 2014. Numerical evaluation of heat transfer enhancement in rocket thrust chambers by wall ribs. Numer. Heat Tr. A Appl. 66(5):488-508. doi: 10.1080/10407782.2014.885233. 
17. Betti, B., D. Bianchi, F. Nasuti, and E. Martelli. 2014. Chemical reaction effects on wall heat flux in liquid rocket thrust chambers. AIAA Paper No. 2014-3675.

18. Gordon, S., and B. J. McBride. 1994. Computer program for calculation of complex chemical equilibrium compositions and applications. NASA RP 1311.

19. Spalart, P. R., and S. R. Allmaras. 1994. A one-equation turbulence model for aerodynamic flow. Rech. Aerospatiale 1:5-21.

20. Kendall, R. M., E .P. Bartlett, R. A. Rindal, and C. B. Moyer. 1968. An analysis of the chemically reacting boundary layer and charring ablator. Part I. Summary report. NASA CR 1060.

21. Sankaran, V. 2007. Computational fluid dynamics modeling of hybrid rocket flowfields. Fundamentals of hybrid rocket combustion and propulsion. Eds. K. K. Kuo and M. J. Chiaverini. Progress in astronautics and aeronautics ser. AIAA. 218:323349.

22. Arisawa, H., and T.B. Brill. 1996. Flash pyrolysis of hydroxyl terminated polybutadiene (HTPB) II: Implications of the kinetics to combustion of organic polymers. Combust. Flame 106:131-143.

23. Ramohalli, K., and J. Yi. 1990. Hybrids revisited. AIAA Paper No. 90-1962.

24. Farbar, E., J. Louwers, and T. Kaya. 2007. Investigation of metallized and nonmetallized hydroxyl terminated polybutadiene/hydrogen peroxide hybrid rockets. J. Propul. Power 23(2):476-486.

25. Coronetti, A., and W. A. Sirignano. 2013. Numerical analysis of hybrid rocket combustion. J. Propul. Power 29(2):371-384.

26. Marano, J. J., and G. D. Holder. 1997. General equation for correlating the thermophysical properties of $n$-paraffins, $n$-olefins, and other homologous series. 1 . Formalism for developing asymptotic behavior correlations. Ind. Eng. Chem. Res. 36(5):1887-1894.

27. Marano, J. J., and G. D. Holder. 1997. General equation for correlating the thermophysical properties of n-paraffins, n-olefins, and other homologous series. 2. Asymptotic behavior correlations for pvt properties. Ind. Eng. Chem. Res. 36(5):18951907.

28. Marano, J. J., and G. D. Holder. 1997. General equation for correlating the thermophysical properties of $n$-paraffins, $n$-olefins, and other homologous series. 3 . Asymptotic behavior correlations for thermal and transport properties. Ind. Eng. Chem. Res. 36(6):2399-2408.

29. Cheng, G. C., R. C. Farmer, H.S. Jones, and J. S. McFarlane. 1994. Numerical simulation of the internal ballistics of a hybrid rocket motor. AIAA Paper No. 940554 .

30. Andersen, J., C. L. Rasmussen, T. Giselsson, and P. Glarborg. 2009. Global combustion mechanisms for use in CFD modeling under oxy-fuel conditions. Energ. Fuel. 23:1379-1389. 